\title{
Inflammatory cytokine expression in patients with sepsis at an intensive care unit
}

\author{
LILI WANG, HONGYAN ZHAO and DONGXU WANG \\ Intensive Care Unit, Daqing Oil Field General Hospital, Daqing, Heilongjiang 163001, P.R. China
}

Received April 17, 2017; Accepted January 18, 2018

DOI: $10.3892 /$ etm.2018.6376

\begin{abstract}
Sepsis is a systemic inflammatory response syndrome caused by infection of bacteria, fungi and/or viruses in clinical patients. It is known that inflammatory cytokine levels have an essential role in the progression of sepsis. The present study investigated the role of inflammatory markers in human peripheral blood mononuclear cells (hPBMCs) of patients with sepsis at an intensive care unit. In addition, the plasma levels of inflammatory cytokines were compared between sepsis patients and healthy individuals. The results demonstrated that the serum levels of interleukin-1, -17 and -6 , as well as tumor necrosis factor- $\alpha$, were upregulated in sepsis patients. The serum levels of high mobility group box 1 and C-reactive protein were increased in sepsis patients compared with those in healthy individuals. The expression levels of nuclear factor- $\kappa \mathrm{B}-\mathrm{p} 65$ and its inhibitor $\mathrm{I} \kappa \mathrm{B} \alpha$, as well as the ratio of $\mathrm{CD} 25^{+}$cells, and the levels of neutrophil gelatinase-associated lipocalin and peptidoglycan recognition protein were higher in hPBMCs in sepsis patients compared with those in healthy individuals. It was also indicated that balance of $\mathrm{T}$ helper type $1 / 2$ cytokines was also disturbed in patients with sepsis compared with that in healthy individuals. In conclusion, these results indicated that inflammation is involved in the progression of sepsis by interfering with the expression of various molecules, suggesting a potential therapeutic strategy for the treatment of sepsis patients.
\end{abstract}

\section{Introduction}

Sepsis is a systemic inflammatory response syndrome caused by infection with bacteria, fungi and/or viruses $(1,2)$. Although sepsis is caused by infection, the development of sepsis is based on a series of inflammatory responses and the pathological processes associated with them $(3,4)$. Biomarkers in serum may be used to diagnose for patients with sepsis (5). Although numerous strategies have been explored for the

Correspondence to: Professor Hongyan Zhao, Intensive Care Unit, Daqing Oil Field General Hospital, 9 Zhong Kang Street, Saertu, Daqing, Heilongjiang 163001, P.R. China

E-mail: zhaohongyanprof@aliyun.com

Key words: sepsis, inflammation, intensive care unit, cytokines treatment of sepsis, affected patients still have an increased risk of mortality $(6,7)$. A previous study also demonstrated that a reduction of inflammatory factors significantly improved metabolic parameters that are beneficial for survival in septic rats (8). In addition, distinct shock phenotypes were apparent, and the effect of early resuscitation according to protocols has been examined in selected cohorts of patients with septic shock (9).

Sepsis is associated with a complex systemic inflammation, which may lead to immune dysfunction, abnormal coagulant function and tissue damage caused by infection with various pathogenic microorganisms, as well as by toxins $(10,11)$. Various studies suggested that sepsis is closely associated with the pathological processes of inflammation $(12,13)$, which may require further elucidation. Sepsis is thought to result from acute and postponed inflammatory responses via the increasing of plasma inflammatory cytokines levels and leukocytes in affected patients $(14,15)$. A previous study also has indicated the role of inflammatory responses in the progression of sepsis, suggesting inhibition of inflammatory responses may contribute to the alleviation of jejunum injury in rats with sepsis (16). In addition, a randomized controlled trial has suggested that reducing lipopolysaccharide-triggered inflammation is beneficial for the treatment of human sepsis by downregulation of the plasma levels of interleukin (IL)-6, IL-8 and tumor necrosis factor (TNF)- $\alpha$ (17). Furthermore, Kaplan et al (18) have indicated that reducing inflammation through inhibition of nuclear factor $(\mathrm{NF})-\kappa \mathrm{B}$ is an efficient strategy for the treatment of sepsis patients. These studies suggest that inflammation is associated with the progression of pathology of sepsis and may be potential target for its treatment.

Systemic inflammatory response syndrome is thought to be associated with the progression of sepsis patients (19). Therefore, detection of markers of the inflammatory response may be considered as a way to evaluate the prognosis of sepsis. The purpose of the present study was to investigate the expression levels of inflammatory cytokines between patients with sepsis and healthy individuals. The importance of inflammatory responses in the evaluation of patients with sepsis was also investigated.

\section{Materials and methods}

Ethical approval and participant consent. A total of 122 patients with sepsis who were admitted to the intensive 
Table I. Sequences of primers used for polymerase chain reaction.

\begin{tabular}{lll}
\hline Gene name & \multicolumn{1}{c}{ Reverse $\left(5^{\prime}-3^{\prime}\right)$} & \multicolumn{1}{c}{ Forward $\left(5^{\prime}-3^{\prime}\right)$} \\
\hline TNF- $\alpha$ & TCCAGACTTCCTTGAGACA & GGCGATTACAGACACAACT \\
IL-1 & GGCTGCTTCCAAACCTTTGA & GAAGACACGGATTCCATGGT \\
IL-6 & GTGAGGAACAAGCCAGAG & TGACCAGAAGAAGGAATGC \\
IL-17 & ATGCACAGCCACCGCGACTT & CTTCATGACTGCCTCCAAGTAG \\
PRP & GCTTGGCACACCTTTTCACATACC & GTCCTCATTCGGGGCACATTCTG \\
N $\alpha$ - $\mathrm{NB}-\mathrm{p} 65$ & CTTCCTCCTCTTCCTCCTC & GCCATCTTCACGCTAAGG \\
PCT & GAGTCAGAGTTCACGGAGTTC & CATGTTCTTCAGCCCCTTTG \\
$\beta-$-actin & GGAGAGCACGCCATGAAG & AAGATTCGCATGCGGTAGAG \\
\hline
\end{tabular}

IL, interleukin; TNF, tumor necrosis factor; NF, nuclear factor; I $\mathrm{KB} \alpha$, inhibitor of NF- $\kappa \mathrm{B}$; PCT, procalcitonin; PRP, peptidoglycan recognition protein.

care unit (ICU) at Daqing Oil Field General Hospital (Daqing, China) without any medication prior to the determination of the clinical parameters and 106 healthy individuals (who did not exhibit symptoms of sepsis or inflammation) were recruited for clinical analysis between January 2014 and August 2015. All patients and healthy volunteers provided written informed consent. The study was approved by the ethics committee of Daqing Oil Field General hospital (Daqing, China).

Reverse transcription-quantitative polymerase chain reaction $(R T-q P C R)$ assay. A total of $15 \mathrm{ml}$ peripheral venous blood was obtained from each patient with sepsis. Human peripheral blood monouclear cells (hPBMCs) were separated by density gradient centrifugation using $10 \mathrm{ml}$ of $0.01 \%$ cesium chloride at $4,000 \mathrm{x}$ g for $30 \mathrm{~min}$ at $4^{\circ} \mathrm{C}$. Total RNA was extracted from hPBMCs cells using RNAzol (Sigma-Aldrich; Merck KGaA, Darmstadt, Germany), and RNase-free DNase was applied to digest total DNA at $37^{\circ} \mathrm{C}$ for $15 \mathrm{~min}$. The RNeasy kit was then used to purify RNA to adjust its concentration to $1 \mu \mathrm{g} / \mu \mathrm{l}$. A total of $2 \mu \mathrm{g}$ RNA was used as the template to synthetize complementary (c)DNA by reacting with reverse transcriptase at $37^{\circ} \mathrm{C}$ for $120 \mathrm{~min}$, at $99^{\circ} \mathrm{C}$ for $4 \mathrm{~min}$ and at $4^{\circ} \mathrm{C}$ for 3 min using the High Capacity cDNA Reverse Transcription kit (Thermo Fisher Scientific, Inc., Waltham, MA, USA) according to the manufacturer's protocol. Subsequently, PCR was employed to amplify the cDNA of neutrophil gelatinase-associated lipocalin (NGAL), peptidoglycan recognition protein (PRP), cluster of differentiation (CD)64, procalcitonin (PCT), NF- $\kappa \mathrm{B}-\mathrm{p} 65$, inhibitor of NF- $\kappa \mathrm{B}(\mathrm{I} \kappa \mathrm{B} \alpha)$, IL-1, IL-17, TNF- $\alpha$ and IL- 6 using the primers listed in Table I to determine the transcription level of the respective mRNA. PCR amplification had preliminary denaturation at $95^{\circ} \mathrm{C}$ for $1 \mathrm{~min}$, followed by 40 cycles of $95^{\circ} \mathrm{C}$ for $30 \mathrm{sec}, 58^{\circ} \mathrm{C}$ for $30 \mathrm{sec}$ and $72^{\circ} \mathrm{C}$ for $10 \mathrm{~min}$. The reaction volume was a total of $20 \mu \mathrm{l}$ containing $50 \mathrm{ng}$ genomic cDNA, $200 \mu \mathrm{M}$ dNTPs, $200 \mu \mathrm{M}$ primers, and Taq DNA polymerase and SYBR-Green (both 2.5 U; Thermo Fisher Scientific, Inc.). $\beta$-Actin was used as the housekeeping gene for the internal control group. Eventually, agarose electrophoresis with $1 \%$ ethidium bromide was adopted to check PCR-amplified products. Changes in relative mRNA expression were calculated by the $2^{-\Delta \Delta \mathrm{Cq}}$ method (20). The results are expressed as the fold change compared with the control.

ELISA. Plasma samples were immediately prepared from peripheral venous blood by centrifugation $\left(2,000 \mathrm{xg}\right.$ at $4^{\circ} \mathrm{C}$ for $10 \mathrm{~min}$ ). Serum levels of TNF- $\alpha$ (cat. no. MBS6080), IL-1 (cat. no. MBS700340), IL-6 (cat. no. MBS3205), high mobility group box 1 (HMGB1; cat. no. MBS4108) and C-reactive protein (CRP; cat. no. MBS910284; all from Thermo Fisher Scientific, Inc.) were analyzed in patients with sepsis using ELISA kits according to the manufacturer's protocols. The balance of T-helper cell type 1 (Th1)/Th2 cytokines was analysed using Th1/Th2 Human Th1/Th2 (7 plex) Multiplex Immunoassay kit (cat. no. ab213389; Abcam, Cambridge, UK) according to the manufacturer's protocol. The serum levels of these cytokines were measured with a micro-plate reader at $570 \mathrm{~nm}$.

Flow cytometry. From the peripheral blood drawn from the patients with sepsis, total leukocytes were extracted using a Human Leukocyte Extract Kit (Invitrogen; Thermo Fisher Scientific, Inc.). The proportion of lymphocytes, granulocytes and mononuclear cells among total leukocytes in the plasma was analyzed by flow cytometry as previously described (21). The hPBMCs was also incubated with fluorescein isothiocyanate-labelled CD25 (1:1,000; cat. no. ab210335; Abcam) for $12 \mathrm{~h}$ at $4^{\circ} \mathrm{C}$. The proportion of hPBMCs presenting the activation marker CD25 was analysed by flow cytometry using FCS Express $^{\mathrm{TM}} 4$ IVD (De Novo Software, Glendale, CA, USA).

Statistical analysis. Statistical analysis was performed using SPSS 19.0 software (IBM Corp., Armonk, NY, USA) and Excel (version 2010; Microsoft Corp., Redmond, WA, USA). All values are expressed as the mean \pm standard error of the mean of triplicate experiments. Differences between groups were analyzed using Student's two-tailed t-test. $\mathrm{P}<0.05$ was considered to indicate a statistically significant difference.

\section{Results}

Characteristics of patients with sepsis. A total of 122 patients with sepsis and 106 healthy individuals were recruited for 
Table II. Characteristics of patients with sepsis at an intensive care unit.

\begin{tabular}{lcc}
\hline Characteristic & $\begin{array}{c}\text { Patients } \\
\text { with sepsis }\end{array}$ & $\begin{array}{c}\text { Healthy } \\
\text { individuals }\end{array}$ \\
\hline Number & 122 & 106 \\
Age (years) & $45.4 \pm 18.3$ & $47.2 \pm 18.6$ \\
Male/female & $60 / 62$ & $50 / 56$ \\
APACHE II score & $15.2 \pm 7.8$ & 0 \\
Type of infection & & \\
Acute pyelonephritis & 28 & 0 \\
Intra-abdominal infection & 32 & 0 \\
Lung infection & 29 & 0 \\
Bloodstream infection & 33 & 0 \\
\hline
\end{tabular}

Values are expressed as mean \pm standard deviation or $n$.

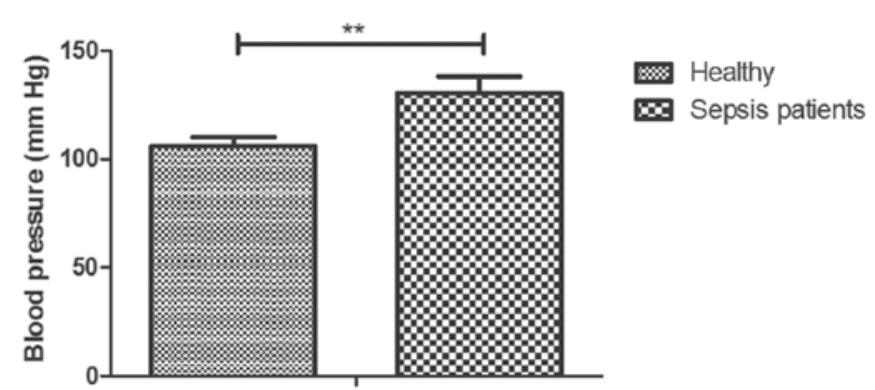

Figure 1. Characteristics of patients with sepsis. Blood pressure of healthy individuals and patients with sepsis at an intensive care unit. ${ }^{* *} \mathrm{P}<0.01$.

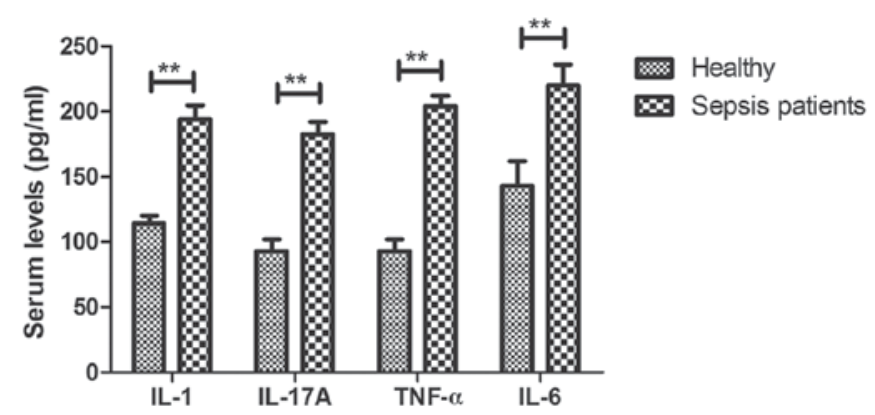

Figure 2. Inflammatory cytokines are increased in serum of patients with sepsis at the ICU. Inflammatory cytokines IL-1, IL-17A, TNF- $\alpha$ and IL-6 in serum in healthy individuals and patients with sepsis at an intensive care unit. ${ }^{* *} \mathrm{P}<0.01$. IL, interleukin; TNF, tumor necrosis factor.

the present clinical analysis. The ratios of males and females among the groups of sepsis patients and healthy individuals were approximately equal. The mean age was $45.4 \pm 18.3$ and $47.2 \pm 18.6$ years in sepsis patients and healthy individuals, respectively. The characteristics of patients with sepsis are summarized in Table II. The blood pressure was higher in sepsis patients than that in healthy individuals (130 vs. $106 \mathrm{~mm} \mathrm{Hg}$; $<0.01$; Fig. 1).

Inflammatory cytokines are increased in serum of patients with sepsis at the ICU. Changes of inflammatory cytokines

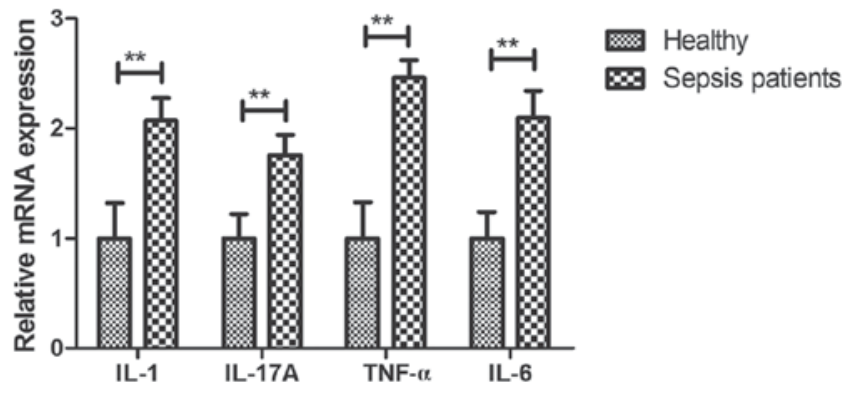

Figure 3. Analysis of inflammatory cytokine mRNA expression in hPBMCs of patients with sepsis at the ICU. Gene expression levels of IL-1, IL-17A, TNF- $\alpha$ and IL-6 in human peripheral blood mononuclear cells in healthy individuals and patients with sepsis at an intensive care unit. ${ }^{* *} \mathrm{P}<0.01$. IL, interleukin; TNF, tumor necrosis factor.

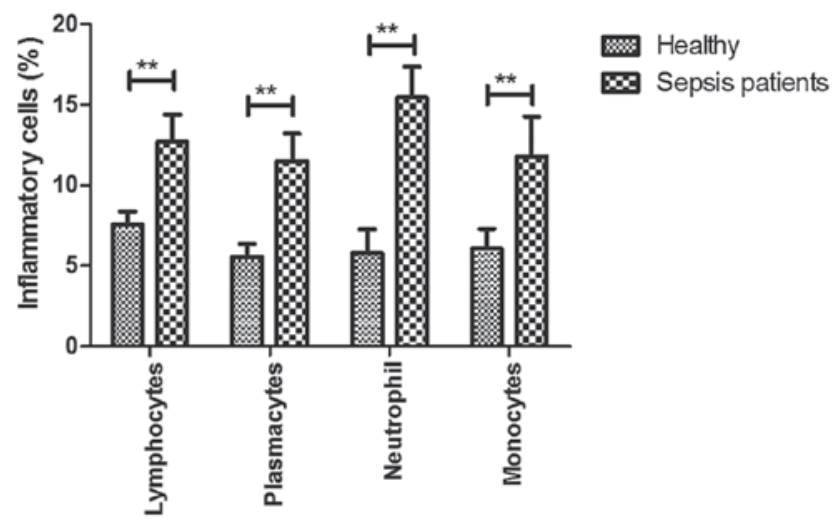

Figure 4. Analysis of inflammatory cells in serum of patients with sepsis at the ICU. Inflammatory cells, including lymphocytes, plasmacytes, neutrophils and monocytes among the total leukocytes in healthy individuals and patients with sepsis at an intensive care unit. ${ }^{* *} \mathrm{P}<0.01$.

in the serum of patients with sepsis were analyzed. The serum levels of IL-1, IL-17, TNF- $\alpha$ and IL-6 were identified to be upregulated in sepsis patients compared with those in healthy individuals $(\mathrm{P}<0.01 ;$ Fig. 2). These results suggest that inflammatory cytokines were obviously upregulated in the serum of patients with sepsis at the ICU.

Analysis of inflammatory cytokine mRNA expression in hPBMCs of patients with sepsis at the ICU. The gene expression levels of inflammatory cytokines in hPBMCs of patients with sepsis were assessed in the present study. The mRNA expression levels of IL-1 (2.07-fold), IL-17 (1.76-fold), TNF- $\alpha$ (2.46-fold) and IL-6 (1.96-fold) were markedly up-regulated in hPBMCs of patients with sepsis compared with that in healthy individuals $(\mathrm{P}<0.01 ;$ Fig. 3$)$. These results suggest that the gene expression levels of inflammatory cytokines are upregulated in hPBMCs of patients with sepsis in an ICU setting.

Analysis of inflammatory cells in serum of patients with sepsis at the ICU. To explore the role of inflammation in the progression of sepsis, changes in the ratio of inflammatory cells were investigated in serum in patients with sepsis. As presented in Fig. 4, the percentages of lymphocytes, plasmacytes, neutrophils and monocytes among the total leukocytes were increased in patients with sepsis at the ICU compared 
A

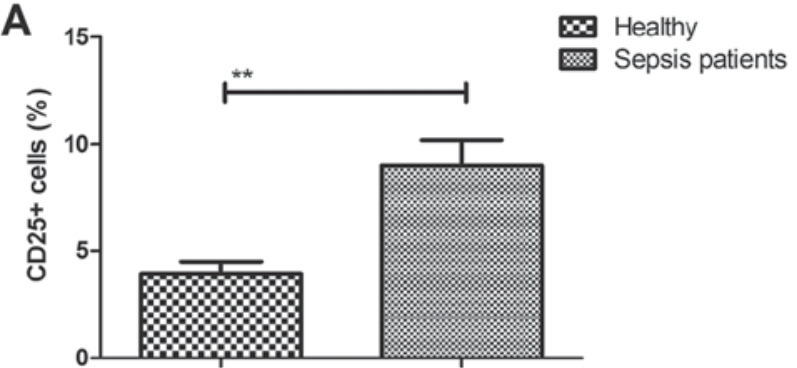

C

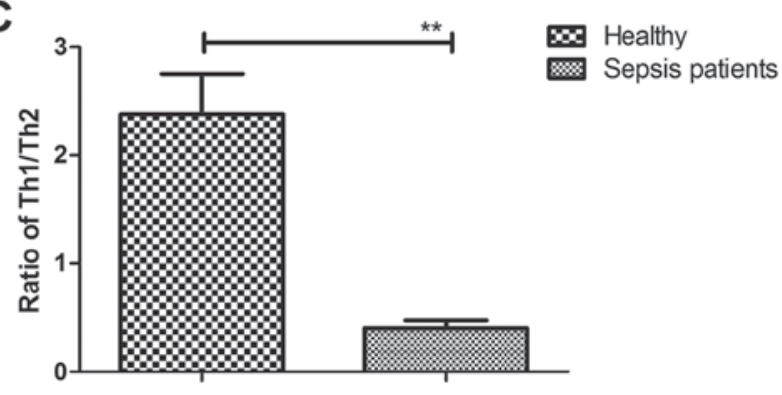

B
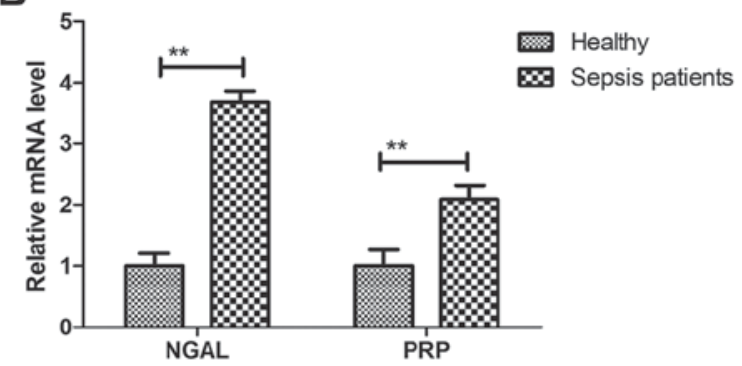

D

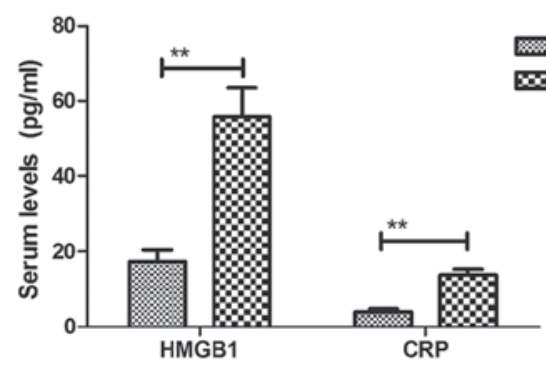

Figure 5. Analysis of biomarkers of inflammatory cytokines in patients with sepsis at the ICU. Analysis of biomarkers of inflammatory cells in healthy individuals and patients with sepsis at an ICU. (A) Percentage of activation maker CD25 cells was increased in patients with sepsis at the ICU. (B) Gene expression levels of NGAL and PRP were significantly upregulated in human peripheral blood mononuclear cells from sepsis patients. (C) The balance of Th1/Th2 cytokines was disturbed in patients with sepsis. (D) Patients with sepsis presented with higher serum levels of HMGB1 and CRP than healthy individuals. ${ }^{* *} \mathrm{P}<0.01$. ICU, intensive care unit; CRP, C-reactive protein; Th1, type 1 T-helper cell; NGAL, neutrophil gelatinase-associated lipocalin; HMGB1, high mobility group box 1 protein; PRP, peptidoglycan recognition protein.

with those in healthy individuals $(\mathrm{P}<0.01)$. These results suggest that inflammatory cells are upregulated in serum of patients with sepsis at the ICU.

Analysis of biomarkers of inflammatory cytokines in patients with sepsis at the ICU. The presentation of biomarkers of inflammatory cytokines on hPBMCs of patients with sepsis at the ICU was then analyzed. The results indicated that the proportion of hPBMCs presenting the activation marker CD25 was significantly increased in sepsis patients compared with that in healthy individuals (9.00 vs. $3.95 \%$; $\mathrm{P}<0.01$; Fig. $5 \mathrm{~A})$. As presented in Fig. 5B, NGAL and PRP were significantly upregulated in hPBMCs of sepsis patients compared with those from healthy individuals (3.67- and 2.09-fold for NGAL and PRP, respectively). The balance of T-helper cell type 1 (Th1)/Th2 cytokines was decreased in patients with sepsis (2.38 vs. $0.41 \%$; $\mathrm{P}<0.01$; Fig. 5C). In addition, the serum levels of HMGB1 and C-reactive protein (CRP) were increased in sepsis patients compared with those in healthy individuals (HMGB1, 55.95 vs. 16.88; CRP, 13.80 vs. 4.10; $\mathrm{P}<0.01$; Fig. 5D). These results suggest that biomarkers of inflammatory cytokines are upregulated in serum of patients with sepsis in an ICU setting.

Analysis of biomarkers of inflammation in hPBMCs of patients with sepsis at the ICU. The gene expression levels of biomarkers of inflammation in hBPMCs of patients with sepsis at the ICU were then explored. The results indicated that the gene expression levels of NF- $\kappa \mathrm{B}-\mathrm{p} 65, \mathrm{I} \kappa \mathrm{B} \alpha, \mathrm{CD} 64$ and PCT were higher in hPBMCs than those in healthy individuals

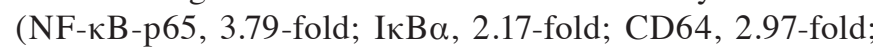
PCT, 2.72-fold; $\mathrm{P}<0.01$; Fig. 6). These results suggest that the

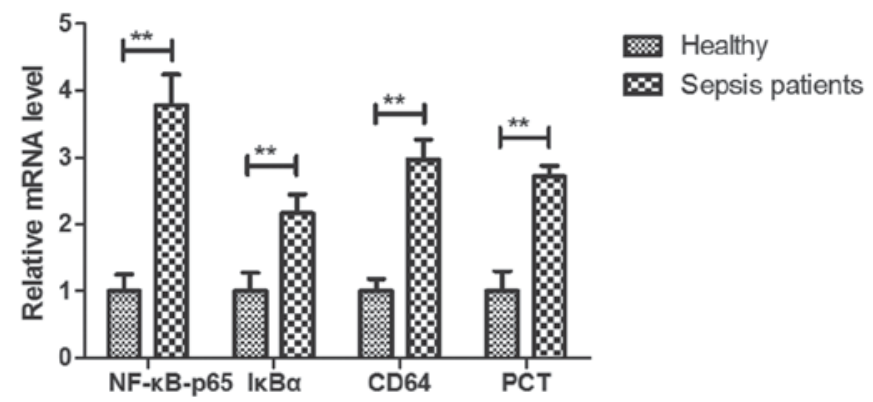

Figure 6. Analysis of biomarkers of inflammation in hPBMCs of patients with sepsis at the ICU. The mRNA expression levels of NF- $\kappa \mathrm{B}-\mathrm{p} 65, \mathrm{I} \kappa \mathrm{B} \alpha$, CD64 and PCT are upregulated in human peripheral blood mononuclear cells in patients with sepsis at an intensive care unit. ${ }^{* *} \mathrm{P}<0.01$. NF, nuclear factor; I $\mathrm{B} \alpha$, inhibitor of $\mathrm{NF}-\kappa \mathrm{B}$; PCT, procalcitonin.

mRNA expression of inflammatory biomarkers in hPBMCs was upregulated in patients with sepsis in an ICU setting.

\section{Discussion}

Sepsis can leads to accumulation of bacterial endotoxins, release of inflammatory mediators and immune dysfunction $(22,23)$. Inflammatory responses are the major reason leading to mortality of patients with sepsis $(24,25)$. The present study analyzed the changes of serum inflammatory cytokines and markers in hPBMCs of patients with sepsis in an ICU setting. The present results indicated that the serum levels of inflammatory cytokines, biomarkers and inflammatory cells were upregulated in patients with sepsis compared with those in healthy individuals. 
Circulating inflammatory cytokines have been identified as mediators of damage in patients with sepsis (26). The present study reported the upregulation of the inflammatory cytokines IL-1, IL-17, TNF- $\alpha$ and IL-6 in sepsis patients compared with those in healthy individuals. Cross (27) suggested that targeting IL-1/IL-17A may improve therapeutic outcomes for patients with sepsis. Studies have also demonstrated that the serum levels of the cytokines TNF- $\alpha$ and IL-6 were increased and that the TNF- $\alpha-308 \mathrm{G} / \mathrm{A}$ polymorphism is associated with post-operative sepsis (28-31). The present study indicated that the serum levels of inflammatory cytokines and the gene expression levels of IL-1, IL-17, TNF- $\alpha$ and IL-6 in hPBMCs were upregulated in patients with sepsis at the ICU compared with those in healthy individuals. Of note, the serum concentrations of inflammatory cells, including lymphocytes, plasmacytes, neutrophil and monocytes among the leukocytes, were markedly increased in patients with sepsis compared with those in healthy individuals.

HMGB1 is regarded as a predicator of organ dysfunction in patients with severe sepsis $(32,33)$. The role of CRP in sepsis has been reported in multidisciplinary studies on patients in the ICU setting $(34,35)$. The present study reported that the serum levels of HMGB1 and CRP were significantly increased in sepsis patients compared with those in healthy individuals. Wang et al (36) reported that attenuating CD4 ${ }^{+}$ CD25 ${ }^{+}$T-regulatory cells ameliorated burn sepsis. In addition, plasma NGAL has been used to diagnose acute kidney injury in patients with systemic inflammatory disease and sepsis (37). Furthermore, peptidoglycan recognition protein is associated with inflammation in patients with bacterial infection $(38,39)$. The present results suggest that biomarkers of inflammatory cytokines are upregulated in serum of patients with sepsis at the ICU compared with that in healthy individuals.

Studies have indicated that inhibition of $N F-\kappa B$ activation is beneficial for the treatment of experimental sepsis $(40,41)$. Song et al (42) reported that benzenediamine derivate FC-98 exhibited anti-inflammatory efficacy against sepsis injury in mice via suppression of c-Jun N-terminal kinase, NF- $\kappa \mathrm{B}$ and interferon regulatory transcription factor 3 signaling pathways. The present study indicated that NF- $\kappa \mathrm{B}$ gene expression levels are higher in hPBMCs of patients with sepsis than those in healthy individuals, which may provide a potential target for the treatment of sepsis.

In conclusion, the present study indicated an upregulation of inflammatory cytokines in the serum of patients with sepsis. These results suggest that inflammatory cytokines are potential targets for the treatment of sepsis patients. It was also indicated that the balance of Th1/Th2 cytokines was decreased in patients with sepsis in an ICU setting compared with that in healthy individuals, which may provide a potential diagnostic tool for patients with sepsis.

\section{Acknowledgements}

Not applicable.

\section{Funding}

No funding was received.

\section{Availability of data and materials}

The datasets used and/or analyzed during the current study are available from the corresponding author on reasonable request.

\section{Authors' contributions}

LW performed the experiments. HZ designed and analysed the experiments. DW analysed the data from the experiments.

\section{Ethical approval and consent to participate}

All patients and healthy volunteers provided written informed consent. The study was approved by the ethics committee of Daqing Oil Field General hospital (Daqing, China).

\section{Consent for publication}

Not applicable.

\section{Competing interests}

The authors declare that they have no competing interests.

\section{References}

1. Guild GN III, Wu B and Scuderi GR: Articulating vs. static antibiotic impregnated spacers in revision total knee arthroplasty for sepsis. A systematic review. J Arthroplasty 29: 558-563, 2014.

2. Serpa Neto A, Veelo DP, Peireira VG, de Assunção MS Manetta JA, Espósito DC and Schultz MJ: Fluid resuscitation with hydroxyethyl starches in patients with sepsis is associated with an increased incidence of acute kidney injury and use of renal replacement therapy: A systematic review and meta-analysis of the literature. J Crit Care 29: 185, 2014.

3. Neto AS, Pereira VG, Manetta JA, Espósito DC and Schultz MJ: Association between static and dynamic thenar near-infrared spectroscopy and mortality in patients with sepsis: A systematic review and meta-analysis. J Trauma Acute Care Surg 76: 226-233, 2014.

4. Patel A, Laffan MA, Waheed U and Brett SJ: Randomised trials of human albumin for adults with sepsis: Systematic review and meta-analysis with trial sequential analysis of all-cause mortality. BMJ 349: g4561, 2014.

5. Nelson GE, Mave V and Gupta A: Biomarkers for sepsis: A review with special attention to India. Biomed Res Int 2014: 264351, 2014.

6. Trivedi V, Bavishi C and Jean R: Impact of obesity on sepsis mortality: A systematic review. J Crit Care 30: 518-524, 2015

7. Wang C, Chi C, Guo L, Wang X, Guo L, Sun J, Sun B, Liu S, Chang X and Li E: Heparin therapy reduces 28-day mortality in adult severe sepsis patients: A systematic review and meta-analysis. Crit Care 18: 563, 2014.

8. Silva LS, Catalão CH, Felippotti TT, Oliveira-Pelegrin GR, Petenusci S, de Freitas LA and Rocha MJ: Curcumin suppresses inflammatory cytokines and heat shock protein 70 release and improves metabolic parameters during experimental sepsis. Pharm Biol 55: 269-276, 2017.

9. Williams JM, Greenslade JH, Dymond CA, Chu K, Brown AF and Lipman J: Characteristics, treatment and outcomes for all emergency department patients fulfilling criteria for septic shock: A prospective observational study. Eur J Emerg Med 25: 97-104, 2016.

10. Gille-Johnson P, Hansson KE and Gårdlund B: Severe sepsis and systemic inflammatory response syndrome in emergency department patients with suspected severe infection. Scand J Infect Dis 45: 186-193, 2013.

11. Fan PC, Chang CH, Tsai MH, Lin SM, Jenq CC, Hsu HH, Chang MY, Tian YC, Hung CC, Fang JT, et al: Predictive value of acute kidney injury in medical intensive care patients with sepsis originating from different infection sites. Am J Med Sci 344: 83-89, 2012. 
12. Chen Z, Ding X, Jin S, Pitt B, Zhang L, Billiar T and Li Q: WISP1- $\alpha v \beta 3$ integrin signaling positively regulates TLR-triggered inflammation response in sepsis induced lung injury. Sci Rep 6: 28841, 2016.

13. Chung HY, Hupe DC, Otto GP, Sprenger M, Bunck AC, Dorer MJ, Bockmeyer CL, Deigner HP, Gräler MH and Claus RA: Acid sphingomyelinase promotes endothelial stress response in systemic inflammation and sepsis. Mol Med 22, 2016.

14. Park JH, Jang JH, Choi EJ, Kim YS, Lee EJ, Jung ID, Han HD, Wu TC, Hung CF, Kang TH and Park YM: Annexin A5 increases survival in murine sepsis model by inhibiting HMGB1-mediated pro-inflammation and coagulation. Mol Med 22, 2016.

15. Dwivedi DJ, Grin PM,Khan M,Prat A,Zhou J,Fox-Robichaud AE, Seidah NG and Liaw PC: Differential expression of PCSK9 modulates infection, inflammation, and coagulation in a murine model of sepsis. Shock 46: 672-680, 2016.

16. Chen YK, Xu YK, Zhang H, Yin JT, Fan X, Liu DD, Fu HY and Wan B: Emodin alleviates jejunum injury in rats with sepsis by inhibiting inflammation response. Biomed Pharmacother 84 1001-1007, 2016

17. Matzneller P, Strommer S, Drucker C, Petroczi K, Schörgenhofer C, Lackner E, Jilma B and Zeitlinger M: Colistin reduces LPS-triggered inflammation in a human sepsis model In vivo: A randomized controlled trial. Clin Pharmacol Ther 101: 773-781, 2016.

18. Kaplan D, Casper TC, Elliott CG, Men S, Pendleton RC, Kraiss LW, Weyrich AS, Grissom CK, Zimmerman GA and Rondina MT: VTE incidence and risk factors in patients with severe sepsis and septic shock. Chest 148: 1224-1230, 2015

19. Chou HL, Han ST, Yeh CF, Tzeng IS, Hsieh TH, Wu CC, Kuan JT and Chen KF: Systemic inflammatory response syndrome is more associated with bacteremia in elderly patients with suspected sepsis in emergency departments. Medicine (Baltimore) 95 e5634, 2016

20. Livak KJ and Schmittgen TD: Analysis of relative gene expression data using real-time quantitative PCR and the 2(-delta delta C(T)) method. Methods 25: 402-408, 2001.

21. Filipova J, Rihova L, Vsianska P, Kufova Z, Kryukova E, Kryukov F and Hajek R: Flow cytometry in immunoglobulin light chain amyloidosis: Short review. Leuk Res: July 13, 2015 (Epub ahead of print).

22. Markwart R, Condotta SA, Requardt RP, Borken F, Schubert K, Weigel C, Bauer M, Griffith TS, Förster M, Brunkhorst FM, et al: Immunosuppression after sepsis: Systemic inflammation and sepsis induce a loss of naïve T-cells but no enduring cell-autonomous defects in T-cell function. PloS One 9: e115094, 2014.

23. Sharma D, Packiriswamy N, Malik A, Lucas PC and Parameswaran N: Nonhematopoietic $\beta$-Arrestin-1 inhibits inflammation in a murine model of polymicrobial sepsis. Am J Pathol 184: 2297-2309, 2014.

24. Wang Y, Braun OO, Zhang S, Norström E and Thorlacius H: Monocytes regulate systemic coagulation and inflammation in abdominal sepsis. Am J Physiol Heart Circ Physiol 308 H540-H547, 2015.

25. Zhang S, Luo L, Wang Y, Gomez MF and Thorlacius H: Nuclear factor of activated $\mathrm{T}$ cells regulates neutrophil recruitment, systemic inflammation, and T-cell dysfunction in abdominal sepsis. Infect Immun 82: 3275-3288, 2014.

26. de Andrade JAA, Gayer CRM, Nogueira NPA, Paes MC, Bastos VLFC, Neto JDCB, Alves SC Jr, Coelho RM da Cunha MGAT, Gomes RN, et al: The effect of thiamine deficiency on inflammation, oxidative stress and cellular migration in an experimental model of sepsis. J Inflamm (Lond) 11: 11, 2014.
27. Cross AS: IL-18/IL-1/IL-17A axis: A novel therapeutic target for neonatal sepsis? Cytokine 86: 1-3, 2016.

28. Gil M, Kim YK, Hong SB and Lee KJ: Naringin decreases TNF- $\alpha$ and HMGB1 release from LPS-stimulated macrophages and improves survival in a CLP-induced sepsis mice. PloS One 11: e0164186, 2016

29. Montoya-Ruiz C, Jaimes FA, Rugeles MT, López JÁ, Bedoya G and Velilla PA: Variants in LTA, TNF, IL1B and IL10 genes associated with the clinical course of sepsis. Immunol Res 64: 1168-1178, 2016

30. Roderburg C, Benz F, Schüller F, Pombeiro I, Hippe HJ, Frey N, Trautwein C, Luedde T, Koch A, Tacke F and Luedde M: Serum levels of TNF receptor ligands are dysregulated in sepsis and predict mortality in critically Ill patients. PloS One 11: e0153765, 2016.

31. Baghel K, Srivastava RN, Chandra A, Goel SK, Agrawal J, Kazmi HR and Raj S: TNF- $\alpha$, IL- 6 , and IL- 8 cytokines and their association with TNF- $\alpha-308 \mathrm{G} / \mathrm{A}$ polymorphism and postoperative sepsis. J Gastrointest Surg 18: 1486-1494, 2014.

32. Karlsson S, Pettila V, Tenhunen J, Laru-Sompa R, Hynninen M and Ruokonen E: HMGB1 as a predictor of organ dysfunction and outcome in patients with severe sepsis. Intensive Care Med 34: 1046-1053, 2008

33. Waterer GW: High-mobility group box 1 (HMGB1) as a potential therapeutic target in sepsis-more questions than answers. Crit Care Med 35: 1205-1206, 2007.

34. Sarathy V and C Y: Comparison of eosinophil count and neutrophillymphocyte count ratio with $\mathrm{C}$-reactive protein levels in patients with sepsis. J Assoc Physicians India 64: 96, 2016.

35. Pradhan S, Ghimire A, Bhattarai B, Khanal B, Pokharel K, Lamsal $\mathrm{M}$ and Koirala S: The role of $\mathrm{C}$-reactive protein as a diagnostic predictor of sepsis in a multidisciplinary intensive care unit of a tertiary care center in Nepal. Indian J Crit Care Med 20: 417-420, 2016

36. Wang SX, Liu QY and Li Y: Lentinan ameliorates burn sepsis by attenuating CD4+ CD25+ tregs. Burns 42: 1513-1521, 2016.

37. Md Ralib A, Mat Nor MB and Pickering JW: Plasma neutrophil gelatinase-associated lipocalin diagnosed acute kidney injury in patients with systemic inflammatory disease and sepsis. Nephrology (Carlton) 22: 412-419, 2017

38. Dziarski R, Platt KA, Gelius E, Steiner H and Gupta D: Defect in neutrophil killing and increased susceptibility to infection with nonpathogenic gram-positive bacteria in peptidoglycan recognition protein-S (PGRP-S)-deficient mice. Blood 102: 689-697, 2003.

39. Michel T, Reichhart JM, Hoffmann JA and Royet J: Drosophila toll is activated by gram-positive bacteria through a circulating peptidoglycan recognition protein. Nature 414: 756-759, 2001.

40. Li H, Qiu D, Gao Q, Wang H and Sun M: Selectively activating melanocortin 4 receptor acts against rat sepsis-induced acute liver injury via HMGB1/TLR4/NF- $\kappa \beta$ signaling pathway. Xi Bao Yu Fen Zi Mian Yi Xue Za Zhi 32: 1055-1059, 2016 (In Chinese).

41. Zhao H, Li S, Zhang H, Wang G, Xu G and Zhang H: Saikosaponin a protects against experimental sepsis via inhibition of NOD2-mediated NF- $\kappa \beta$ activation. Exp Ther Med 10: 823-827, 2015.

42. Song Y, Liu X, Yue H, Ji J, Dou H and Hou Y: Anti-inflammatory effects of benzenediamine derivate FC-98 on sepsis injury in mice via suppression of JNK, NF- $\kappa \beta$ and IRF3 signaling pathways. Mol Immunol 67: 183-192, 2015. 